\title{
DESENVOLVIMENTO DE INTERFACE PARA ANÁLISE NUMÉRICA PARA A QUEIMA DE PELOTAS NO POT GRATE DA SAMARCO MINERAÇÃO*
}

\section{Resumo}

\author{
Maycon Athayde \\ Luiz Claudio Von Sperling Cotta ${ }^{2}$ \\ Luis Felipe Kusler Passani \\ André Carlos Contini ${ }^{4}$ \\ Leonardo Barboza Trindade
}

O processo de pelotização consiste na aglomeração e posterior tratamento térmico das pelotas, ajustando as propriedades químicas e mecânicas para o transporte ao reator siderúrgico. A otimização e aperfeiçoamento do processo no forno pode ser realizado experimentalmente utilizando um pot grate. Trata-se de um equipamento no qual uma carga de pelotas cruas é submetida a condições similares às encontradas no processo industrial. Contudo, um projeto de experimentos em um pot grate pode levar semanas. Além disso, alguns parâmetros como: taxas das reações e balanço de energia são difíceis de serem monitorados. Tendo em vista isso, o presente trabalho buscou desenvolver um software de simulação para avaliar o comportamento das pelotas em um pot grate de maneira rápida e prática. Os resultados mostram uma interface amigável para a avaliação da temperatura de pelota, umidade da água, queima do carbono e balanço de energia. Os modelos implementados foram comparados e validados com trabalhos publicados na literatura. $O$ modelo também serve como uma ferramenta de Projetos e Experimentos no Pot, uma vez que permite testes mais rápidos e de custo mais baixo.

Palavras-chave: Pelotização; Pot grate; Software.

\section{INTERFACE DEVELOPMENT FOR NUMERICAL ANALYSIS OF FIRING PELLETS IN THE POT GRATE SAMARCO}

\section{Abstract}

The pelletization process consists in balling and subsequent thermal treatment of the pellets by adjusting the chemical and mechanical properties for shipping to ironmaking. The optimization and process improvement in the furnace can be performed experimentally using a pot grate. This is a facility in which a charge of raw pellets is subjected to conditions similar to those observed in the industrial process. However, an experimental design in a pot grate can take days. In addition, some parameters such as: rates of reactions and energy balance are difficult to monitor. Based on that, the present study aimed to develop a simulation software to evaluate the behavior of pellets in a grate pot quickly and conveniently. The results show a friendly interface for the evaluation of pellet temperature, water moisture, carbon burning and energy balance. The implemented models were compared and validated with published studies. The model also projects and serves as a tool in pot experiments, since it allows for faster testing and lower cost.

Keywords: Pelletizing; Pot grate; Software.

Engenheiro Metalurgista, MSc, Eng., Samarco Mineração, Anchieta, ES, Brasil.

Engenheiro Metalurgista, Eng., Samarco Mineração, Anchieta, ES, Brasil.

Engenheiro Químico, Doutorando em Engenharia Química, Equipe Técnica, STE-Pesquisa e Desenvolvimento, Porto Alegre, RS, Brasil.

4 Físico, Mestre em Eng. Metalúrgica, Equipe técnica, STE-Pesquisa e Desenvolvimento, Porto Alegre, RS, Brasil.

Físico, Doutor em Eng. Metalúrgica, Diretor, STE Pesquisa e Desenvolvimento, Porto Alegre, RS, Brasil. 


\section{INTRODUÇÃO}

Pelotização é um processo usado para agregar valor aos finos de minério [1]. A qualidade e a otimização desse tipo de processo é garantida principalmente com experimentos realizados em planta e testes realizados em planta piloto (pot grate). Além dessas duas abordagens, já existem modelos matemáticos, publicados na literatura, que podem fornecer resultados tão confiáveis quanto os obtidos experimentalmente.

$\mathrm{Na}$ tabela 1 estão apresentados alguns dos principais estudos e as considerações que foram realizadas em cada abordagem.

\begin{tabular}{|c|c|c|c|c|c|c|c|c|c|c|}
\hline $\begin{array}{c}\text { Tabela } 1 . \\
\text { Considerações }\end{array}$ & $\begin{array}{l}\text { Hasenack } \\
\text { [2] }\end{array}$ & $\begin{array}{c}\text { Thurlby } \\
\text { [3] }\end{array}$ & $\begin{array}{l}\text { Seshadri } \\
\text { [4] }\end{array}$ & $\begin{array}{l}\text { Voskamp } \\
\text { [5] }\end{array}$ & $\begin{array}{c}\text { Afzal } \\
{[6]}\end{array}$ & $\begin{array}{l}\text { Küçükada } \\
\text { [7] }\end{array}$ & $\begin{array}{c}\text { Pomerleau } \\
\text { [8] }\end{array}$ & $\begin{array}{l}\text { Majumder } \\
{[9]}\end{array}$ & $\begin{array}{c}\text { Sadrnezhaad } \\
\text { [10] }\end{array}$ & $\begin{array}{c}\text { Barati } \\
\text { [11] }\end{array}$ \\
\hline Ano & 1975 & 1979 & 1985 & 1992 & 1994 & 1994 & 2005 & 2009 & 2008 & 2008 \\
\hline \multicolumn{11}{|l|}{ Modelo de pot grate } \\
\hline Água & 0 & 0 & 0 & 0 & & 0 & 0 & 0 & O & 0 \\
\hline Carbono & & & & & & 0 & 0 & 0 & 0 & 0 \\
\hline Magnetita & 0 & & & - & & & 0 & & 0 & 0 \\
\hline Dolomita & & & & & & & 0 & & & 0 \\
\hline Goethita & & 0 & & & & & & & & \\
\hline Calcita & & & & & & & 0 & 0 & 0 & 0 \\
\hline \multicolumn{11}{|l|}{ Modelo de forno } \\
\hline $\begin{array}{l}\text { Comunicação entre as } \\
\text { zonas }\end{array}$ & ○ & ○ & & 0 & 0 & & 0 & ○ & ○ & \\
\hline Análise da rede de gás & & & & & 0 & & 0 & & & \\
\hline Ventiladores & & 0 & & 0 & 0 & & 0 & & & \\
\hline $\begin{array}{l}\text { Perda de carga nos } \\
\text { dutos }\end{array}$ & & & & 0 & ○ & & & & & \\
\hline Vazamentos no forno & & 0 & & 0 & 0 & & & & & \\
\hline $\begin{array}{l}\text { Avaliação do carro de } \\
\text { grelha }\end{array}$ & 0 & 0 & & 0 & & & & & & ○ \\
\hline $\begin{array}{l}\text { Consumo dos } \\
\text { queimadores }\end{array}$ & & & & & & & ○ & & ○ & \\
\hline $\begin{array}{l}\text { Modelagem da } \\
\text { qualidade }\end{array}$ & & 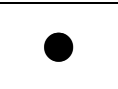 & & & & & & & 0 & \\
\hline
\end{tabular}

No presente estudo, buscou-se desenvolver um software amigável que permite ao usuário uma análise detalhada do processo de queima em um pot grate. Pode-se avaliar variáveis do processo como: taxa das reações químicas, balanço de energia em cada zona e perfil de temperatura, auxiliando o engenheiro/técnico na tomada de decisão.

Outra potencial utilidade da ferramenta é o treinamento de novos profissionais, facilitando o conhecimento e o entendimento do complexo processo de pelotização de pelotas.

\section{MATERIAIS E MÉTODOS}

O software desenvolvido foi denominado Grate Software (GS). Ele é baseado numa modelagem da transferência de calor entre o leito de pelotas e o gás que permeia o 
leito durante o processo de secagem, queima e resfriamento de um pot grate. $O$ desenvolvimento do modelo prevê algumas considerações bem aceitas pela literatura conforme demonstrado na tabela anterior, quais sejam:

I. O pot grate é adiabático;

II. O pot grate possui simetria cilíndrica;

III. A contribuição da radiação é incluída no coeficiente de calor convectivo $h$;

IV. A transferência de calor no leito ocorre apenas na direção vertical;

V. A condução de calor entre as pelotas é desprezada;

VI. O calor transferido entre a pelota e o gás é apenas por convecção;

VII. A temperatura da pelota é uniforme em todos os pontos da pelota $(B i<0,1)$;

VIII. O fluxo de gás é uniforme dentro do leito. Não são consideradas regiões preferenciais de escoamento;

IX. O calor das reações químicas afeta apenas a temperatura da pelota, ou seja, não há fontes de calor no gás.

\subsection{Modelagem Matemática}

As equações de transferência de calor entre o leito de pelotas e o gás é dado pelas equações (1) e (2).

$$
\begin{gathered}
\rho_{p} C_{p} \frac{\partial T_{p}}{\partial t}=h A\left(T_{g}-T_{p}\right)+\sum_{i=1}^{5} R_{i} \Delta H_{i} \\
G C_{p_{g}} \frac{\partial T_{g}}{\partial z}=-h A\left(T_{g}-T_{p}\right)
\end{gathered}
$$

O coeficiente de transferência de calor é calculado segundo a equação (3).

$$
h=\frac{\lambda_{g}}{d_{p}}\left(2+1,1 \operatorname{Re}^{\frac{1}{2}} \operatorname{Pr}^{\frac{1}{3}}\right)
$$

A área superficial de troca de calor $A$ é resolvida conforme equação (4).

$$
A=\frac{6\left(1-\varepsilon_{b}\right)}{\varphi d_{p}}
$$

O termo $R_{i}$ é definido como a taxa da reação, que ao ser multiplicado pela $\Delta H_{i}$ da reação, fornece a liberação/consumo de energia devido às reações químicas. $\mathrm{Na}$ tabela 2, são apresentadas as seis reações químicas consideradas na presente abordagem.

Tabela 2. Reações químicas implementadas.

\begin{tabular}{cc}
\hline $\mathrm{CaCO}_{3}\left(\mathrm{MgCO}_{3}\right)_{(\mathrm{s})} \rightarrow \mathrm{CaO}_{(\mathrm{s})}+\mathrm{MgO}_{(\mathrm{s})}+2 \mathrm{CO}_{2(\mathrm{~g})}$ & $\mathrm{H}_{2} \mathrm{O}_{(\mathrm{l})} \rightarrow \mathrm{H}_{2} \mathrm{O}_{(\mathrm{g})}$ \\
Reação de decomposição da dolomita & Reação de secagem \\
\hline $4 \mathrm{Fe}_{3} \mathrm{O}_{4(\mathrm{~s})}+\mathrm{O}_{2(\mathrm{~g})} \rightarrow 6 \mathrm{Fe}_{2} \mathrm{O}_{3(\mathrm{~s})}$ & $\mathrm{C}_{(\mathrm{s})}+\mathrm{O}_{2(\mathrm{~g})} \rightarrow \mathrm{CO}_{2(\mathrm{~g})}$ \\
Reação de oxidação da magnetita & Reação de combustão \\
\hline $2 \mathrm{FeO}(\mathrm{OH})_{(s)} \rightarrow \mathrm{Fe}_{2} \mathrm{O}_{3_{(s)}}+\mathrm{H}_{2} \mathrm{O}_{(\mathrm{g})}$ & $\mathrm{CaCO}_{3(\mathrm{~s})} \rightarrow \mathrm{CaO}_{(\mathrm{s})}+\mathrm{CO}_{2(\mathrm{~g})}$ \\
Reação da goethita & Reação de calcinação da calcita \\
\hline
\end{tabular}

$\mathrm{Na}$ implementação adotada, a queda de pressão $\Delta P$ é uma das condições de contorno. Com isso, o valor do fluxo mássico $G$ pode ser obtido utilizando a equação 5, proposta por Ergun [12]. 


$$
\frac{d P}{d z}=\frac{150 \mu_{g}(1-\varepsilon)^{2}}{\left(\varphi d_{p}\right)^{2} \varepsilon^{3} \rho_{g}} G+\frac{1,75(1-\varepsilon)}{\varphi d_{p} \varepsilon^{3} \rho_{g}} G^{2}
$$

O procedimento numérico do modelo matemático pode ser visualizado no fluxograma apresentado na figura 1. Nota-se que o algoritmo é baseado num processo iterativo onde é necessário que a pressão tenha convergência para cada passo de tempo.
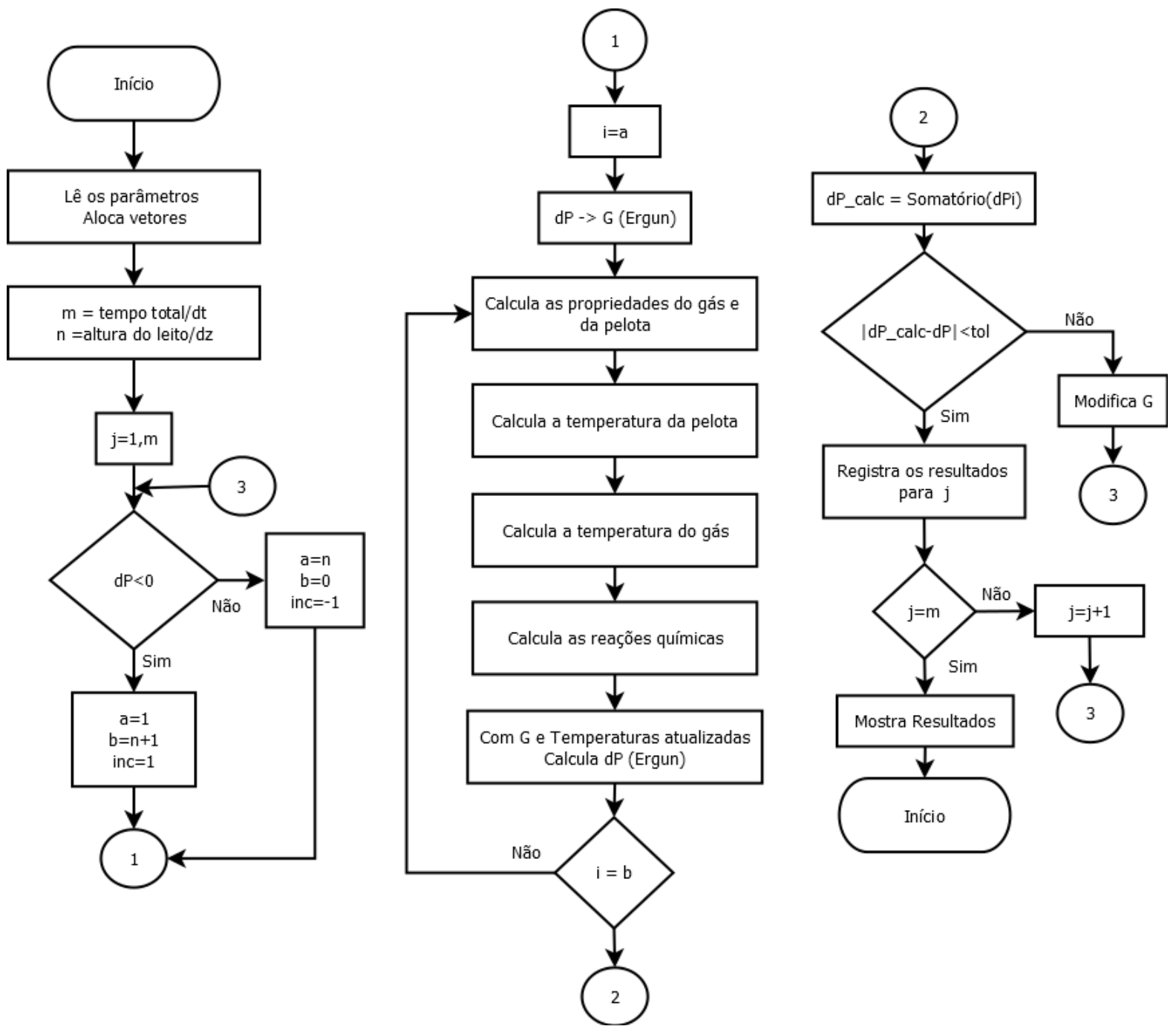

Figura 1. Fluxograma do modelo desenvolvido.

O algoritmo foi construído utilizando a linguagem Java (IDE Eclipse). Além de ser uma linguagem com um processamento rápido, ela permite o desenvolvimento de uma interface gráfica amigável. Na figura 2 é possível ver (à esquerda) a aba onde são realizadas as entradas do modelo, tais como: composição física e química da pelota, propriedades do leito e a disposição dos termopares. No lado direito, são apresentadas as abas: temperatura da pelota, fração de água e balanço de energia em cada zona do forno. 
Output

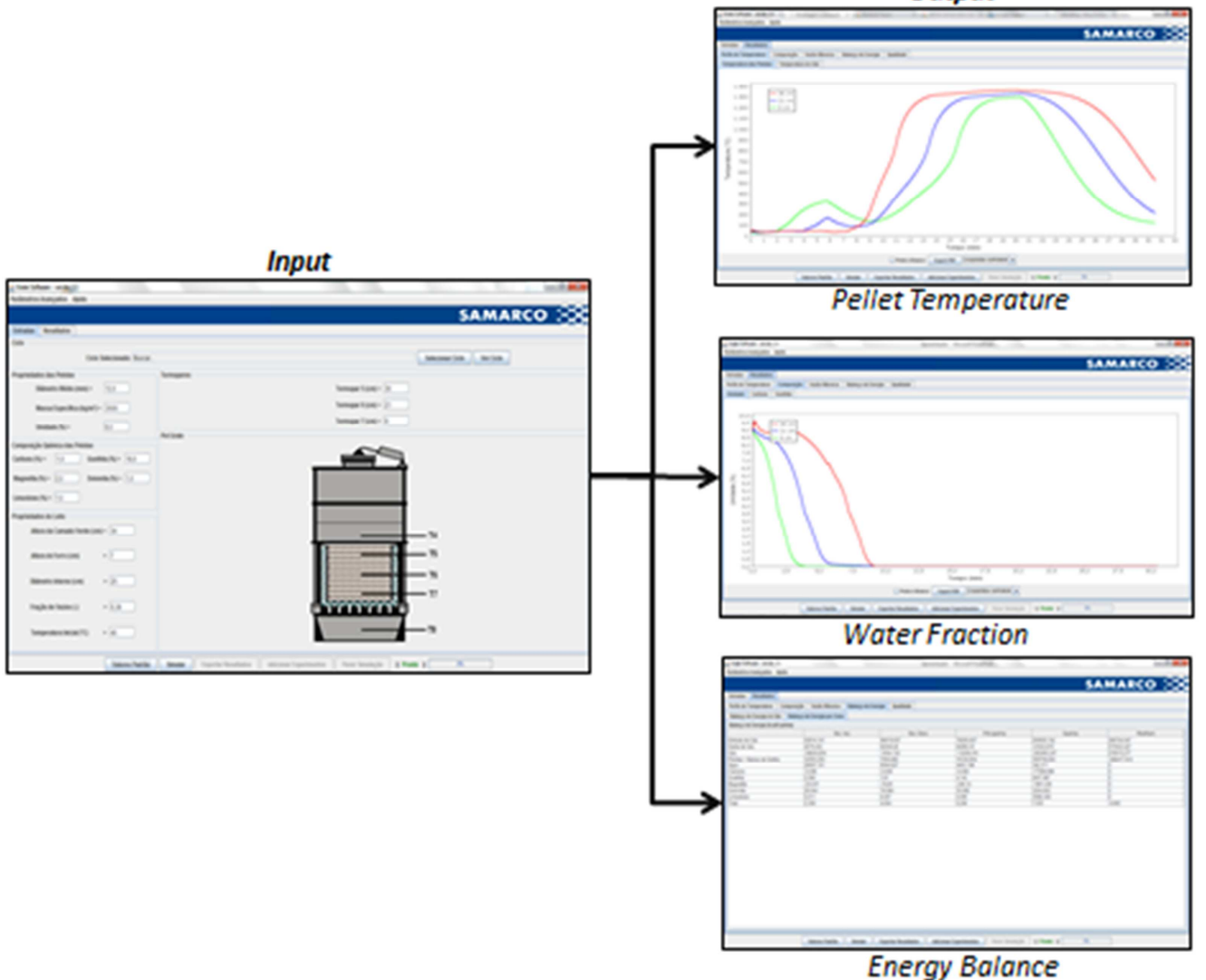

Figura 2. Algumas janelas demostrando entradas e saída do software.

\section{RESULTADOS E DISCUSSÃO}

\subsection{Validação do Modelo}

A validação do modelo foi realizada comparando a temperatura calculada da pelota em diferentes posições do leito com a temperatura medida em queimas realizadas no pot grate. Na figura 3 (a) é mostrada a comparação dos resultados obtidos pelo modelo e os resultados experimentais de Seshadri [4]. Os resultados se mostraram satisfatórios, especialmente na região de 0 a 25 minutos (entre o início da secagem e o final da região de queima). Na região de mudança de fluxo, que ocorre da queima para o resfriamento, teve-se dificuldade para se conseguir uma aferição adequada, principalmente na parte superior do leito.

$\mathrm{Na}$ figura 3 (b) é apresentada a comparação com os resultados experimentais de Thurby [3]. No presente caso, conseguiu-se uma melhor aferição dos dados na parte superior do leito. Na parte inferior, os resultados da modelagem ficaram com uma temperatura superior ao esperado.

A comparação dos resultados experimentais do trabalho de Barati [11] está mostrada na figura 3 (c). Observa-se que, tanto a parte superior quanto a parte inferior do leito, tiveram uma razoável aferição em praticamente todo o processo.

As diferenças dos resultados de modelagem frente aos dados da literatura podem ter algumas divergências devido à falta de informação de alguns parâmetros ou mesmo por algum ponto da modelagem não ter sido feito de maneira adequada para o determinado pot grate. 
(a)

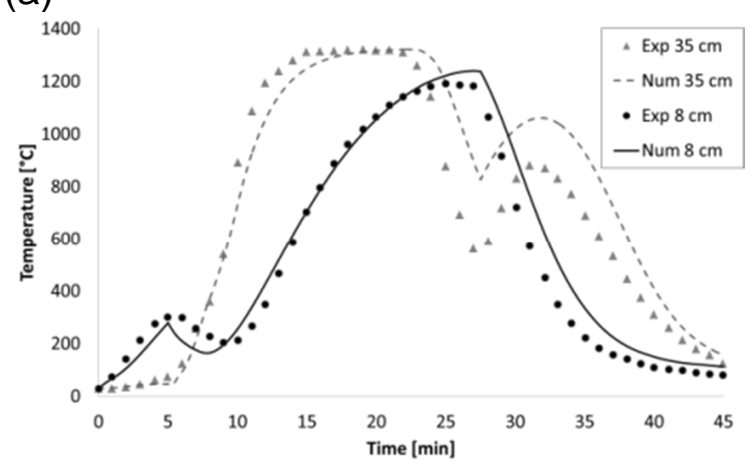

(b)

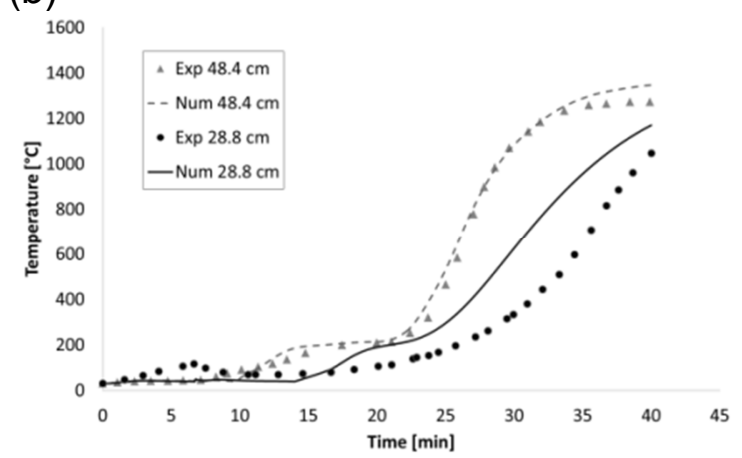

(c)

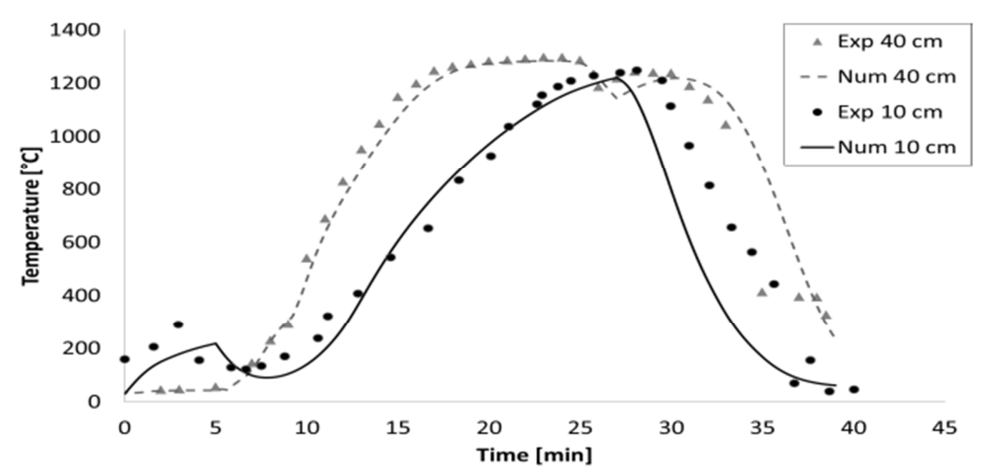

Figura 3. (a) Thurby [3] (b) Seshadri [4] (c) Barati [11].

Após a validação do modelo com dados disponíveis na literatura, o trabalho foi direcionado para realização de teste experimentais em um pot grate disponível na empresa Samarco. Na tabela 3, pode-se observar o balanço energia em cada uma das regiões do forno. Com essa análise é possível conhecer em qual região cada reação se inicia, quanta energia ela libera/absorve, prever a energia que é transportada pelo ar na entrada e na saída de cada zona e avaliar a magnitude que fica armazenada no leito e nas barras de grelha.

Tabela 3. Balanço de energia das zonas do forno.

\begin{tabular}{|c|c|c|c|c|c|c|c|c|c|c|c|c|c|c|c|}
\hline $\mathrm{Kcal} / \mathrm{kg}$ & Sec. Asc & Sec. Asc II & Sec. Desc & Pre Queima 1 & Queima 2 & Queima 3 & Queima 4 & Queima 5 & Queima 6 & Queima 7 & Queima 8 & Queima 9 & Queima 10 & Resfr 1 & Resfr 2 \\
\hline Entrada de Gás & 35,8 & 27,0 & 5,6 & 14,3 & 32,1 & 23,9 & 21,9 & 20,4 & 34,1 & 14,5 & 14,5 & 14,3 & 9,4 & 0,0 & 0,0 \\
\hline Saída de Gás & 0,4 & $-0,9$ & 1,0 & 11,9 & 30,3 & 21,3 & 17,9 & 13,9 & 15,1 & 3,8 & 2,6 & 1,5 & 0,3 & $-267,9$ & $-50,2$ \\
\hline Água & $-18,2$ & $-15,5$ & $-7,6$ & $-2,6$ & 0,0 & 0,0 & 0,0 & 0,0 & 0,0 & 0,0 & 0,0 & 0,0 & 0,0 & 0,0 & 0,0 \\
\hline Carbono & 0,0 & 0,0 & 0,0 & 0,0 & 12,1 & 16,9 & 17,4 & 16,5 & 14,2 & 0,6 & 0,0 & 0,0 & 0,0 & 0,0 & 0,0 \\
\hline Dolomita & 0,0 & 0,0 & 0,0 & $-0,4$ & $-1,5$ & $-1,0$ & $-0,5$ & 0,0 & 0,0 & 0,0 & 0,0 & 0,0 & 0,0 & 0,0 & 0,0 \\
\hline Limestone & 0,0 & 0,0 & 0,0 & 0,0 & $-1,2$ & $-0,9$ & $-0,8$ & $-0,6$ & 0,0 & 0,0 & 0,0 & 0,0 & 0,0 & 0,0 & 0,0 \\
\hline Desbalanço & 0,0 & 0,0 & 0,0 & 0,0 & 0,0 & 0,0 & 0,0 & 0,0 & 0,0 & 0,0 & 0,0 & 0,0 & 0,0 & 0,0 & 0,0 \\
\hline
\end{tabular}

A quantidade de água presente na pelota em função do tempo, em muitos casos, é uma variável importante para a melhora do processo. No entanto, esse tipo de resultado é muito complicado de quantificar em um teste experimental. Com isso, foi desenvolvido desenvolvida uma feature no software capaz de avaliar a umidade da pelota em função do tempo, conforme mostrado na figura 4. 


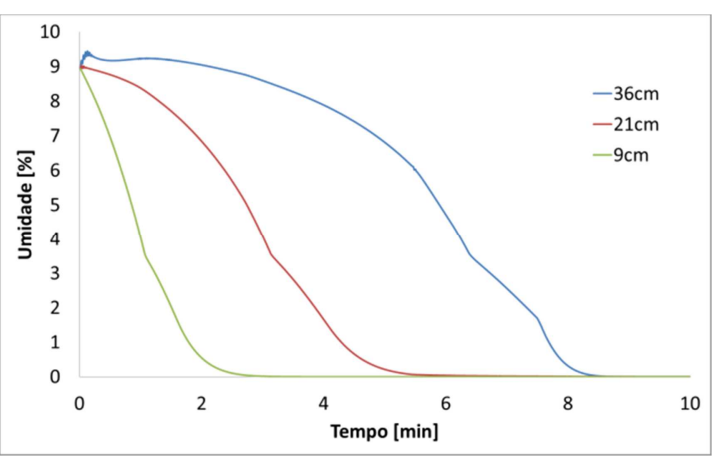

Figura 4. Porcentagem de água na pelota.

Outra saída apresentada pelo modelo é a porcentagem de carbono em função do tempo, conforme mostrado na figura 5. Pode-se notar que a queima do carbono dentro das pelotas inicia-se em um tempo para cada altura do leito, iniciando pela camada superior do leito.

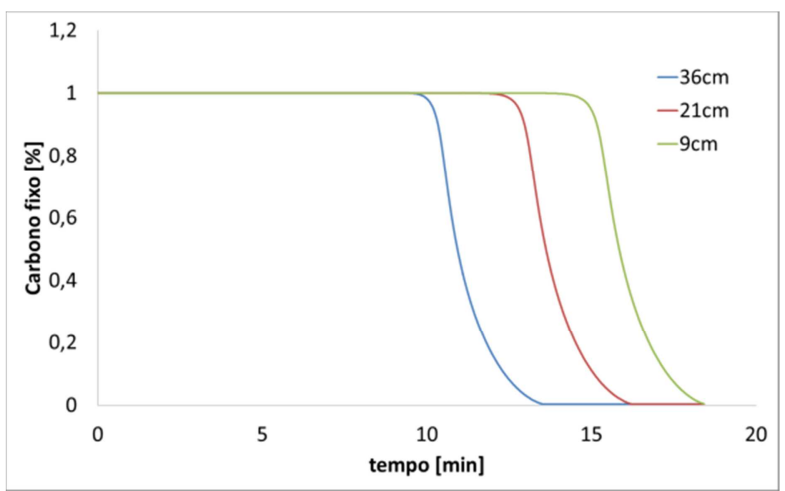

Figura 5. Porcentagem de carbono na pelota.

\section{CONCLUSÃO}

O presente trabalho possibilitou o desenvolvimento de um software de simulação do processo de queima em um pot grate. Com isso, conseguiu-se avaliar variáveis do processo difíceis de serem quantificadas experimentalmente. Curvas de temperatura de pelota em diferentes alturas do leito foram comparadas com três trabalhos da literatura e o resultado foi satisfatório. O próximo passo deste projeto é desenvolver um modelo completo de forno de grelha móvel capaz de prever e otimizar o processo de pelotização de maneira rápida e segura.

\section{LISTA DE SÍMBOLOS}

$A=$ Área superficial $\left[m^{-1}\right]$

$B i=$ Número de Biot $[-]$

$C_{p}=$ Calor específico $\left[\mathrm{Jkg}^{-1} \mathrm{~K}^{-1}\right]$

$C_{p_{g}}=$ Calor específico do gás $\left[\mathrm{Jkg}^{-1} \mathrm{~K}^{-1}\right]$

$d_{p}=$ diâmetro da pelota $[\mathrm{m}]$

$G=$ Fluxo mássico de gás $\left[\mathrm{kgm}^{-2} \mathrm{~s}^{-1}\right]$

$h=$ Coeficiente de convecção $\left[\mathrm{Jm}^{-2} \mathrm{~s}^{-1} \mathrm{~K}^{-1}\right]$

$P=\operatorname{pressão}[\mathrm{Pa}]$

$\operatorname{Pr}=$ Número de Prandtl $[-]$

$R_{i}=$ Taxa de reação $i\left[\mathrm{kgm}^{-3} \mathrm{~s}^{-1}\right]$ 
Re $=$ Número de Reynolds $[-]$

$T_{g}=$ Temperatura do gás $[K]$

$T_{p}=$ Temperatura da pelota $[K]$

$z=$ Altura do leito $[\mathrm{m}]$

$\Delta H_{i}=$ Entalpia da reação $i\left[\mathrm{Jkg}^{-1}\right]$

$\varepsilon_{b}=$ Fração de vazios [-]

$\varphi=$ Esfericidade da pelota $[-]$

$\lambda_{g}=$ Condutividade térmica $\left[\mathrm{Jm}^{-1} \mathrm{~K}^{-1} \mathrm{~S}^{-1}\right]$

$\mu_{g}=$ Viscosidade dinâmica do gás $\left[\mathrm{kgm}^{-1} \mathrm{~s}^{-1}\right]$

$\rho_{g}=$ Densidade do gás $\left[\mathrm{kgm}^{-3}\right]$

$\rho_{p}=$ densidade da pelota $\left[\mathrm{kgm}^{-3}\right]$

\section{REFERÊNCIAS}

1 Meyer K. Pelletizing of Iron Ores. Berlin; 1980.

2 Hasenack NA, Lebelle PAM, Kooy JJ. Induration process for pellets on a moving strand. Met Soc. 1975;

3 Thurlby JA, Batterham RJ, Turner RE. Development and validation of a mathematical model for the moving grate induration of iron pellets. Int J Miner Process. 1979;6:43-64.

4 Seshadri V, Pereira R. Mathematical simulation of induration of iron ore pellets in pot grate. 4 th Int Symp Agglom. Toronto; 1985;729-44.

5 Voskamp JH, J. B. Digital simulation of the steady state behavior of moving bed processes. Meas Control. 1975;8:23-32.

6 Afzal M, Cross M. GASFLO - Airflow distribution evaluation software tool for ducting systems of pellet induration processes. Appl Math Model. 1994;18:408-14.

7 Küçükada K, Thibault J. Modelling of a pilot scale iron ore pellet induration furnace. Can Metall Q. 1994;33(1):1-12.

8 Pomerleau D, Hodouin D, Poulin É. A first principle simulator of an iron oxide pellet induration furnace - an application to optimal tuning. Can Metall Q. 2005;44:571-81.

9 Majumder S, Natekar PV, Runkana V. Virtual indurator: A tool for simulation of induration of wet iron ore pellets on a moving grate. Comput Chem Eng. 2009 Jun;33(6):1141-52.

10 Sadrnezhaad SK, Ferdowsi A, Payab H. Mathematical model for a straight grate iron ore pellet induration process of industrial scale. Comput Mater Sci. Elsevier B.V.; 2008;44(2):296-302.

11 Barati M. Dynamic simulation of pellet induration process in straight-grate system. Int J Miner Process. Elsevier B.V.; 2008 Dec;89(1-4):30-9.

12 Ergun S. Fluid flow through packed columns. Chem Eng Prog. 1952;2(23). 